\title{
Challenges of dehydration result in a behavioral shift in invasive toads
}

\author{
Carla B. Madelaire ${ }^{1,2}$ (D) Adriana M. G. Barsotti ${ }^{1,2}$ (D) Carla Wagener $^{2}$ (D) $\cdot$ Yuri Y. Vieira Sugano $^{1}$ (D) \\ James Baxter-Gilbert ${ }^{2}$ (D) $\cdot$ Fernando R. Gomes ${ }^{1}$ (D) $\cdot$ John $^{\text {Measey }}{ }^{2}$ (B)
}

Received: 18 February 2020 / Revised: 29 May 2020 / Accepted: 3 June 2020

(C) Springer-Verlag GmbH Germany, part of Springer Nature 2020

\begin{abstract}
The adaptive nature of invasive species facilitates their survival in conditions that differ markedly from their native range. Behavioral changes in invasive populations are poorly explored but offer a wide potential when combined with physiological traits. For amphibians invading xeric habitats, finding water is important to function optimally and avoid dehydration. The waterfinding hypothesis postulates that survival can be enhanced through the increased behavioral ability to find water. We tested the water-finding hypothesis in guttural toads (Sclerophrys gutturalis) from their native range and an invasive population. Additionally, we tested if artificially elevated corticosterone levels, which increase during dehydration, affect behavioral traits linked to water balance. In a labyrinth experiment, we observed the toads' ability to find water in different hydration states (100\%, $90 \%$, and $80 \%$ ). We found that individuals from the invasive population took longer to engage in water-searching behavior and spent more time close to the water source after finding it. Toads from the invasive population were also more active, and at $90 \%$ hydration, their attempts to find water increased. Moreover, artificially increasing corticosterone in fully hydrated invasive toads increased water-finding success. Our experiments demonstrated that invasive toads show water-conservation behaviors that can optimize water balance and might facilitate survival in an invaded xeric environment. Additionally, we suggest a link between elevated corticosterone levels and water-finding success. Our results lend support to the importance of behavior in successful invasions and the modulation of water-finding behavior by corticosterone.
\end{abstract}

\section{Significant statement}

Invasion success is associated with behavioral and physiological adaptations of invasive species. For anuran species invading xeric habitats, the ability to find water is an important behavioral trait. Using a labyrinth experiment and toads (Sclerophrys gutturalis) dehydrated at different levels, we observed that individuals invading a hydric challenging habitat showed advantageous water-conservation behaviors (e.g., taking longer to engage in water-searching behavior and spent more time close to the water source after finding it) compared to toads from the native range. Transdermal treatment with corticosterone, a hormone that increases its plasma concentrations under dehydration, increased success of finding water in 100\% hydrated animals. Our results indicate that, compared to the native population, invasive toads display water-conservation behaviors that might improve survival rates in a novel xeric environment and that experimental corticosterone elevation modulates this water-finding behavior.

Keywords Anura $\cdot$ Corticosterone $\cdot$ Dehydration $\cdot$ Invasion biology $\cdot$ Locomotor activity $\cdot$ Water-searching behavior

Communicated by A. Taylor Baugh

Electronic supplementary material The online version of this article (https://doi.org/10.1007/s00265-020-02866-5) contains supplementary material, which is available to authorized users.

Carla B. Madelaire

cmadelaire@yahoo.com.br

Extended author information available on the last page of the article

\section{Introduction}

Biological invasions are increasing with no apparent decline in the rate of introductions (Seebens et al. 2018). Not all introductions, however, result in crossing the boundaries from introduction to establishment and onto invasion (c.f., Blackburn et al. 2011). To better predict taxa that may become invasive, invasion biologists are looking for species traits, or syndromes, that contribute towards establishment success 
(e.g., Kueffer et al. 2013; Novoa et al. 2020). Many such studies concentrate on the physical attributes of invaders, and the changes to conditions in new ranges are of key importance to successful invasions (Duncan and Williams 2002). Behavioral changes, on the other hand, can also play a key role in the establishment of a founding animal population (Chapple et al. 2012) and their consequent spread (Holway and Suarez 1999; Gruber et al. 2017a). Furthermore, behavioral and physiological traits might be more plastic than morphological characteristics and manifest themselves earlier in the invasion process (Chapple et al. 2012; Carere and Gherardi 2013; Walls and Gabor 2019).

Among vertebrates, the rates of establishment of amphibian invaders are increasing sharply (Capinha et al. 2017), largely as a result of a dramatic rise in the numbers of traded individuals (Kraus 2008; Herrel and van der Meijden 2014). These amphibian invasions often result in negative impacts on native species (Bucciarelli et al. 2014; Nunes et al. 2019). A small number of taxa have been intensively studied (van Wilgen et al. 2018), and these species are thought to have evolved numerous morphological, physiological, and behavioral traits that facilitate their successful invasion (e.g., Gruber et al. 2017a; Louppe et al. 2017). Paramount among these is the ability to operate under novel hydric conditions, especially with respect to managing water balance. Dehydration affects numerous physiological aspects for amphibians (Moore and Gatten Jr 1989; Wilson and Morley 2003), including thermoregulation (Anderson and Andrade 2017) and locomotor performance (e.g. Tingley et al. 2012; Titon Jr and Gomes 2017; Vimercati et al. 2018). In this way, living in xeric environments has the potential to impact a suite of morphological, physiological, and behavioral traits for amphibians (Bentley and Schmidt-Nielsen 1966; Hillman 1982; Jørgensen 1997).

Considering the highly permeable skin of amphibians and the associated high rates of evaporative water loss (Toledo and Jared 1993), water balance maintenance is relevant to a number of physiological parameters that compel individuals to locate water to rehydrate (Titon Jr et al. 2010). As such, there is a clear advantage for amphibians to exhibit behaviors that promote their ability to maintain hydric homeostasis; the maintenance of which may have physiological underpinnings (Hillyard 1999). Cruz-Piedrahita et al. (2018) found that anuran species from semiarid biomes found water more quickly than their mesic counterparts, i.e., the "water-finding hypothesis." Thus, the ability to find water, along with other behavioral strategies to avoid dehydration, can play an important role in anuran survival especially in dry novel environments (Child et al. 2009; Prates and Navas 2009).

In response to dehydration, toads sharply increase plasma corticosterone (CORT) levels (Barsotti et al. 2019), indicating that dehydration can trigger a physiological stress response. The acute elevation in CORT helps organisms cope with stressful conditions by mediating different effects on organisms, including behavioral changes (Sapolsky et al. 2000; Jessop et al. 2018). Glucocorticoids (GC) act on different aspects of water balance physiology in mammals, including potentiating the effects of angiotensin II (ANG II) mediating drinking behavior through GC type II receptors in the brain (Ganesan and Summers 1989; Sumners et al. 1991; Takei 2000). Thus, increased CORT during periods of dehydration might also mediate water balance in anurans, including acting on the efficiency of water-searching behavior.

Evidence that terrestrial invasive anurans maximize water conservation behaviorally has been found in cane toads (Rhinella marina), which were introduced to Australia in 1935 as a biological control agent (Lever 2001). Adult cane toads occupy shelters that minimize water loss (Schwarzkopf and Alford 1996; Seebacher and Alford 2002; Tingley and Shine 2011), while metamorphs adjust their dispersal behavior to optimize access to water (Child et al. 2009). Counterintuitively, rates of evaporative water loss are higher in cane toads from arid environments when compared to populations from more mesic environments in Australia. This suggests that toads from the xeric area may rely on access to water ponds more heavily and rapidly absorb water when it is available (Tingley et al. 2012; Brusch et al. 2019). The guttural toad (Sclerophrys gutturalis) which faces a high dehydration potential in their invasive range in Cape Town, South Africa, shows no changes in rates of water uptake less than 20 years after their introduction (Vimercati et al. 2018). Thus, invasive guttural toads may use other strategies to cope with dehydration in their novel xeric habitat, such as differential water-searching behaviors, when compared to the native population.

In this study, we tested whether an invasive population, which is habituated to annual periods of desiccation in their invaded range, approaches the challenge of finding water differently than a native population from a mesic environment. To do this, we compared the water-searching behavior of guttural toads from native and invasive populations in South Africa. We hypothesized that guttural toads from the invasive population, which were exposed to dehydrating conditions, would have an enhanced behavioral ability to search for and conserve water compared to those from the native population and that these behaviors would be exaggerated for toads as the level of dehydration increases. To test this hypothesis, we observed individuals with different levels of hydration in a radial arm labyrinth containing a single water source to assess water-searching-associated behavior, including (1) the latency to start moving, (2) total attempts to find the water, (3) time to find the water, (4) time spent hydrating, (5) time spent within the arm containing the water, (6) total time spent moving, and (7) total time not moving. Moreover, considering CORT levels increase in response to dehydration and its possible role in mediating water-searching behavior, we predicted that an acute increase in CORT would improve a toad's efficiency for finding water. To test this hypothesis, we performed water- 
searching experiments in individuals treated with CORT via transdermal application, simulating an acute elevation of plasma CORT levels, and compared their responses to that of toads treated with a control.

\section{Materials and methods}

\section{Study species}

The guttural toad (Sclerophrys gutturalis) is native to a large region of Africa, from Ethiopia to East London in South Africa, and from Angola to Mozambique (Telford et al. 2019). They invaded several locations outside of their native range, including Mauritius, Réunion, and Constantia (a periurban area in Cape Town), as well as range extensions within their southern African distribution (Measey et al. 2017). Genetic analysis shows all invasions originated from the Durban area (Telford et al. 2019). The invasion in Cape Town was first identified from calling individuals in 2000 (De Villiers 2006), and it is presumed that they were the result of an accidental introduction of eggs or larvae (Telford et al. 2019). Following their introduction, it was nearly 10 years before the established population started expanding (Vimercati et al. 2017). Toads within the Cape Town invasion display increased endurance when dehydrated and spend more time in a water-conserving posture (Vimercati et al. 2018). In addition, female toads have a marked capital breeding and sustained resource allocation to growth (Vimercati et al. 2019).

\section{Collection and maintenance of guttural toads}

We captured guttural toads from two matching peri-urban areas within their native (14 individuals from Durban $75 \mathrm{~m}$ a.s.l., $29^{\circ} 47^{\prime} \mathrm{S}, 31^{\circ} 01^{\prime} \mathrm{E}, 16$ to 23 February 2019) and invasive range (15 individuals from Cape Town $87 \mathrm{~m}$ a.s.l., $34^{\circ} 01^{\prime} \mathrm{S}, 18^{\circ} 25^{\prime} \mathrm{E}$, 17 to 27 January 2019). These same areas were previously used in comparative studies between native and invasive populations of this species (Vimercati et al. 2018, 2019) and represent invaded and source populations (see Telford et al. 2019). Adult male toads were collected by hand. We chose to capture animals of a single sex as intersex differences in hormone levels and behavior may confound analyses. Immediately after capture, animals had their bladder emptied (Titon Jr et al. 2010) and were weighed using a portable balance $( \pm 0.01 \mathrm{~g}$, WTB 2000, Radwag, Radom, Poland) (Vimercati et al. 2018). Toads were then transferred into individually labeled 1-L plastic tubs and transported to the laboratory.

Toads were maintained in the laboratory and kept individually in plastic boxes $(43.0[\mathrm{~L}] \times 28.5[\mathrm{~W}] \times 26.5[\mathrm{H}] \mathrm{cm})$ lined with leaf litter and with free access to water. The animals were fed laboratory-reared crickets (Acheta domesticus) ad libitum. The toads, food, and water availability were checked daily, and the boxes cleaned as required. The boxes were kept in a room with constant temperature $\left(22^{\circ} \mathrm{C} \pm 1^{\circ} \mathrm{C}\right)$ and relative humidity $(40 \% \pm 1 \%)$.

\section{Dehydration protocol}

Following the protocol developed by Titon Jr et al. (2010), toads were placed in a box $(43.0[\mathrm{~L}] \times 28.5[\mathrm{~W}] \times 26.5[\mathrm{H}]$ $\mathrm{cm}$ ) filled to a depth of $1 \mathrm{~cm}$ with aged tap water for at least 2 $\mathrm{h}$, to ensure that they were fully hydrated (i.e., achieving an asymptotic mass). Each toad was then carefully blotted on tissue paper to remove excess water and had their bladder emptied. The registered body mass ( $\mathrm{g}$ ) was considered the standard mass (hydration level of $100 \%$ ). To achieve 90 or $80 \%$ dehydration level, a toad was subsequently placed inside a dry plastic box $(43.0[\mathrm{~L}] \times 28.5[\mathrm{~W}] \times 26.5[\mathrm{H}] \mathrm{cm})$ covered with a mesh lid. An electric fan was then placed above the box to increase air circulation around the toad. Toads were weighed $( \pm 0.01 \mathrm{~g})$ at regular intervals, until they achieved $90 \%$ or $80 \%$ of the standard body mass. The amount of time to dehydrate a toad varied between 3 to $8 \mathrm{~h}$, depending on the individual, their body mass, and the assigned treatment.

\section{Water search experiments}

We constructed radial arm mazes (hereafter referred to as labyrinths), from corrugated plastic, with eight arms around a central arena, resembling an asterisk (Cruz-Piedrahita et al. 2018). Labyrinth walls were $4 \mathrm{~cm}$ high and the central arena $35 \mathrm{~cm}$ in diameter, from which each arm was $13 \mathrm{~cm}$ long and $4 \mathrm{~cm}$ wide. At the end of each arm, we placed a Petri dish containing a standardized amount of dry cotton wool. One of the eight Petri dishes was then randomly assigned to be soaked in $25 \mathrm{ml}$ of aged tap water. The entire apparatus was covered with a piece of glass $(65 \times 65 \mathrm{~cm})$ preventing escape. We conducted three labyrinth tests simultaneously and ran them for $12 \mathrm{~h}$. The trials began at $18 \mathrm{~h} 00$, since we observed (during collections) that guttural toads in South Africa were most active at night. The room was temperature controlled with an air conditioner $\left(22^{\circ} \mathrm{C} \pm 2{ }^{\circ} \mathrm{C}\right)$, and we monitored this with a data logger. We filmed the toads with an infrared CCTV camera and DVR setup, with cameras mounted above the labyrinths. Before each trial, we placed an individual toad at the center of the labyrinth and covered with an opaque plastic container for $15 \mathrm{~min}$ (i.e., at $17 \mathrm{~h} 45$ ). Once the container was gently removed, releasing the toad into the arena, the trial began. The next morning, the toads were removed from their labyrinths, weighed $( \pm 0.01 \mathrm{~g})$ and returned to their maintenance boxes with food. Each toad was tested once per treatment, for a total of three individual trials (i.e., once at $80 \%, 90 \%$, and $100 \%$ hydration level). The order of the treatment and the position of the water in the labyrinth were randomly assigned. Different 
trials for the same individual were carried out after an interval of at least 5 days to allow recovery from the manipulation and dehydration treatment. For each trial, the animal was assigned to a different labyrinth.

\section{Corticosterone transdermal treatment}

CORT solutions were prepared following Assis et al. (2015) and Madelaire et al. (2019). Working concentrations were defined on the basis of increase of CORT levels after dehydration stress in toads (Barsotti et al. 2019). Briefly, $200.0 \mathrm{mg}$ of corticosterone (Sigma - 27840) was diluted in $500 \mu \mathrm{L}$ of $99 \%$ ethanol as a carrier solution. Afterwards, $1000 \mu \mathrm{L}$ of sesame oil was added to the solution and homogenized to obtain a $200 \mu \mathrm{g} \mu \mathrm{L}^{-1}$ solution of CORT. Steroid solutions remained in an open vial overnight to allow evaporation of the ethanol carrier solution. Afterwards, $100 \mu \mathrm{L}$ of this solution $\left(200 \mu \mathrm{g}^{-1}\right)$ was diluted in $900 \mu \mathrm{L}$ of sesame oil and homogenized to obtain a solution with a concentration of $20 \mu \mathrm{g} \mathrm{L}^{-1}$ of CORT. Pure sesame oil was used as a control.

Ten toads from the invasive population were randomly chosen to be tested. Forty-five minutes before they were placed in the labyrinth (Water search experiments, see above), each fully hydrated toad received $10 \mu \mathrm{L}$ of the designated treatment (sesame oil, $200 \mu \mathrm{g}$ of CORT or $2000 \mu \mathrm{g}$ of CORT) onto the upper dorsum, behind the parotid glands, using a micropipette. Following this application, access to water was restricted to assure hormone absorption, and the animal was released in the labyrinth $1 \mathrm{~h}$ after this application, when CORT levels are known to peak (Assis et al. 2015; Madelaire et al. 2019). Once treated, toad behavior was recorded using the same setup as before (Water search experiments, see above) for the next $2 \mathrm{~h}$.

\section{Validation of dermal applications of CORT}

Following completion of the water search experiment, we checked whether the CORT treatment increased the levels of CORT in the toads' plasma. Six toads were treated with $200 \mu \mathrm{g}$ of corticosterone, and one blood sample was taken from each individual at 0 [captivity baseline $(N=6)], 30(N$ $=2), 45(N=2)$, and $60(N=2)$ min after application. After 10 days, these toads went through the same procedure after being treated with $2000 \mu \mathrm{g}$ of corticosterone. The blood sample $(\sim 100 \mu \mathrm{l})$ was taken through cardiac puncture using previously heparinized $1-\mathrm{ml}$ syringes and $26 \mathrm{G} \times$ $1.25 \mathrm{~mm}$ needles within $3 \mathrm{~min}$ of handling to avoid stress influence on captivity baseline CORT levels (Romero and Reed 2005; Tylan et al. 2020), then it was spun in a microcentrifuge at $604 \mathrm{~g}$ for $4 \mathrm{~min}$ and kept at $-80^{\circ} \mathrm{C}$ until the corticosterone measurements (Corticosterone assay, see below).

\section{Corticosterone assay}

Plasma samples were extracted with ether, according to Mendonça et al. (1996) and Madelaire et al. (2019). Each plasma sample was added to $3 \mathrm{~mL}$ of ether, which was then vortexed for $30 \mathrm{~s}$ and centrifuged $\left(4^{\circ} \mathrm{C}, 9 \mathrm{~min}\right.$, at $217 \mathrm{~g}$ ). Following this, samples were placed in a $-80{ }^{\circ} \mathrm{C}$ freezer for $7 \mathrm{~min}$, and the liquid phase was transferred to a new test tube. These test tubes were kept under laminar flow at room temperature, until all ether evaporated (approximately $24 \mathrm{~h}$ ). The samples were then re-suspended in EIA buffer, and CORT was assayed using EIA kits (Cayman Chemical® Corticosterone: item 500655), according to manufacturer's instructions. Sensitivities of CORT were $22.84 \mathrm{pg} \mathrm{mL}^{-1}$.

\section{Video analysis}

We analyzed the video recordings from water search experiments with Behavioral Observation Research Interactive Software (BORIS), an open-source software for behavioral coding (Friard and Gamba 2016). All trials were recorded (see Water search experiment above); however, files from one of the native trials ( $100 \%$ hydration) later became corrupted; therefore, 41 videos from the native population (14 animals * 3 trials for hydration levels - 1) and 45 videos from the invasive population (15 animals $* 3$ trials) were useable. Each trial spanned from the moment that the toad was released until the end of the video recording, totaling $12 \mathrm{~h}$. Duration metrics are expressed as a proportion of total trial duration, while latency metrics are expressed in seconds (see Supplementary material for complete ethogram, as well as R script used for summary of results). To minimize observer bias, the guidelines to all behaviors were established before analyzing the recorded data. For consistency, the video scoring and analysis was conducted by a single researcher (YS), who was blind for what animals corresponded to the native or invasive population but not blind for the hydration treatment. Additionally, half of the videos were also analyzed by another author (CBM), independently and manually, to assess the accuracy of recorded scores.

- For each video, we calculated the following variables: Latency to start moving - the time taken (in seconds) for toads to start moving after being released from the opaque plastic container within the arena. Total attempts to find water - the number of times each toad entered $2 / 3$ of their bodies into the arm of the labyrinth before finding the water. Time to find water - the duration (in seconds) it took for an individual to find the arm of the labyrinth containing the wet cotton wool and making physical contact with watersoaked cotton wool in the petri dish. The total number of attempts, as well as the time to find water, was not recorded for trials in which animals did not find water. Time spent 
hydrating - the proportion of total experimental time the individual spent in physical contact with the water-soaked cotton wool in petri dish. Time spent within the arm containing water - the proportion of total experimental time the individual spent within the arm of the labyrinth containing the water-soaked cotton wool without making physical contact with it. Total time spent moving - the proportion of total experimental time the individual spent moving around the labyrinth. Time spent not moving - the proportion of total experimental time the individual spent not moving in the labyrinth, not including inactivity during hydration.

\section{Data analysis}

To understand how hydration level and population origin affected behavioral traits, we modeled the dependent variables (latency to start moving, total attempts to find the water, time to find the water, time spent hydrating, time spent within the arm containing the water, total time spent moving, and time spent not moving) as a function of hydration level of toads when entering the labyrinth (continuous variable ranging from 93.7 to 86.3 in the $90 \%$ dehydration group and 79.3 to $69.0 \%$ in the $80 \%$ dehydration group), population origin (Cape Town or Durban), the addition of these variables, and their interaction. Considering that body condition (BC) can affect locomotion, $\mathrm{BC}$ was included as a random factor, along with individual. We used nlme (Bates et al. 2015) and bbmle (Bolker 2009) to construct general linear mixed models (GLMM).
Since these models have different numbers of parameters, we calculated the second-order Akaike information criterion (AICc; Akaike 1974), which penalizes the likelihood of a given model as a function of the number of parameters and corrects for low sample sizes. The AICc value $(\mathrm{dAICc} \leq 2.0)$ and model weight from each selected model were considered in the results (Tables 1 and 2) (Burnham and Anderson 2002; Bates et al. 2015; Luke 2017). We also calculated the $95 \%$ confidence intervals (CI) for the parameter estimates (Arnold 2010 using lsmeans (Lenth 2016). We considered the fixed factor significant when the CI did not include zero (Arnold 2010). We used a principal component analysis (PCA) (function prcomp) using all behavior variables. Given that the pattern of covariation may vary between populations, we ran the PCA separately for native and invasive toads. A chi-square analysis was performed to test the success rate of finding water between groups (control, 200 and $2000 \mu \mathrm{g}$ of CORT). To understand how CORT treatment affected behavioral traits, we modeled the dependent variables (latency to start moving, total attempts to find the water, time to find the water, time spent hydrating, time spent within the arm containing the water, total time spent moving, and time spent not moving) as a function of treatment received prior toads entering the labyrinth (categorical variable: control, 200, or $2000 \mu \mathrm{g}$ of CORT). Considering that body condition (BC) can affect locomotion, $\mathrm{BC}$ was included as a random factor, along with treatment order and individual. All analyses were performed at in R software (version 3.5.1; R Core Team, https://www.Rproject.org/2019).
Table 1 Selected models tested for behavioral variables and hydration level in invasive (Cape Town) and native (Durban) populations of Sclerophrys gutturalis

\begin{tabular}{lllll}
\hline Models & AICc & dAICc & df & Weight \\
\hline Movement latency $\sim$ hydration level & 1236.5 & 0.0 & 5 & 0.63 \\
Movement latency $\sim$ hydration level + population & 1238.1 & 1.7 & 6 & 0.27 \\
Attempts $\sim$ hydration level + population & 557.4 & 0.0 & 6 & 0.43 \\
Attempts $\sim$ hydration level & 558.3 & 0.8 & 5 & 0.28 \\
Attempts $\sim$ hydration level*population & 558.4 & 1.0 & 7 & 0.27 \\
Time to find water $\sim$ null & 1611.4 & 0.0 & 4 & 0.38 \\
Time to find water $\sim$ population & 1612.3 & 0.9 & 5 & 0.24 \\
Time to find water $\sim$ hydration level & 1612.7 & 1.3 & 5 & 0.20 \\
Time spent hydrating $\sim$ hydration level & 60.0 & 0.0 & 5 & 0.65 \\
Time spent hydrating $\sim$ hydration level + population & 62.0 & 2.0 & 6 & 0.24 \\
Arm time $\sim$ population & -41.2 & 0.0 & 5 & 0.67 \\
Movement time $\sim$ population & -65.2 & 0.0 & 5 & 0.60 \\
Not moving $\sim$ hydration level + population & 55.7 & 0.0 & 6 & 0.43 \\
Not moving $\sim$ hydration level & 55.8 & 0.1 & 5 & 0.41 \\
Not moving $\sim$ hydration level * population & -57.6 & 2.0 & 7 & 0.16 \\
\hline
\end{tabular}

Movement latency, latency to start moving; attempts, total attempts to find water; arm time, time spent within the arm containing water; movement time, total time spent moving; not moving, time spent not moving; hydration level, level of individual hydration before place the animal in the labyrinth; population, origin of the population (native or invasive) 
Table 2 Selected models tested for behavioral variables after treatment (sesame oil and $200 \mu \mathrm{g}$ or $2000 \mu \mathrm{g}$ of CORT) in Sclerophrys gutturalis

\begin{tabular}{lllll}
\hline Models & AICc & dAICc & df & Weight \\
\hline Movement latency $\sim$ treatment & 340.1 & 0.0 & 7 & 0.58 \\
Movement latency $\sim$ null & 340.8 & 0.7 & 5 & 0.42 \\
Attempts $\sim$ null & 188.4 & 0.0 & 5 & 0.72 \\
Attempts $\sim$ treatment & 190.4 & 1.9 & 7 & 0.28 \\
Time to find water $\sim$ null & 316.6 & 0.0 & 5 & 0.73 \\
Time to find water $\sim$ treatment & 318.6 & 2.0 & 7 & 0.27 \\
Time spent hydrating $\sim$ null & -9.2 & 0.0 & 5 & 0.83 \\
Arm time $\sim$ null & -20.4 & 0.0 & 5 & 0.55 \\
Arm time $\sim$ treatment & -20.0 & 0.4 & 7 & 0.45 \\
Movement time $\sim$ null & -10.9 & 0.0 & 5 & 0.87 \\
Movement time $\sim$ treatment & -7.1 & 3.8 & 7 & 0.13 \\
\hline
\end{tabular}

Movement latency, latency to start moving; attempts, total attempts to find water; arm time, time spent within the arm containing water; movement time, total time spent moving; treatment, 3 levels of treatment: sesame oil and 200 or $2000 \mu \mathrm{g}$ of corticosterone

\section{Results}

Across all trials, the majority of the animals successfully found water. Animals failed to find water in one (hydration level $100 \%$ ) of 45 trials (2\%) for the invasive population and in four of 41 trials $(10 \%)$ for the native population (three animals at hydration level $100 \%$; one animal at hydration level 90\%).

\section{Water-searching behavior}

The selected models for water-searching behavior are displayed in Table 1. Individuals from the invasive population at $100 \%$ and $90 \%$ hydration levels took longer to start moving once released within the arena, compared to the native population (Fig. 1, Table 1; CI for invasive population + hydration levels: $35.4-315.0$ ). At $80 \%$ hydration, the latency to start moving was not different between populations (Fig. 1, Table 1; CI for native population + hydration levels: -22.4 265.0). The GLMM indicated that there was no difference between populations in the time to find water. Time spent hydrating corresponded significantly with hydration level (i.e., animals that were more dehydrated spent more time at the water source) (Fig. 2, Table 1; CI, 0.44-0.60), but no difference in hydration time between populations was detected in the graphs (Fig. 2, Table 1; CI for invasive population + hydration levels, $0.39-0.63$; CI for native population + hydration levels, $0.41-0.65)$. Following hydration, toads from the invasive population spent considerably more time within the arm containing water (i.e., they did not move away from the water source; Fig. 3, Table 1; CI for invasive population + hydration levels, $0.08-0.21$; CI for native population +
Fig. 1 Latency to start moving for native and invasive populations at different hydration levels $(80,90$, and $100 \%$ ). Squares (invasive population, Cape Town) and triangles (native population, Durban) represent how long each animal took to start moving, in seconds, once released into the labyrinth. Boxplots display the median, 10th, 25th, 75th, and 90th quantiles of observations. Within all hydration levels, animals from the invasive population took significantly longer to move than their native counterparts. $(N=40 / 41$ for native, $N=44 / 45$ for invasive; one outlier was removed from the graph but not from the analysis: latency to move $=2663$ seconds, from the native population, $100 \%$ hydration level; one individual from the invasive population had the first hour of the video corrupted and was removed from this metric)

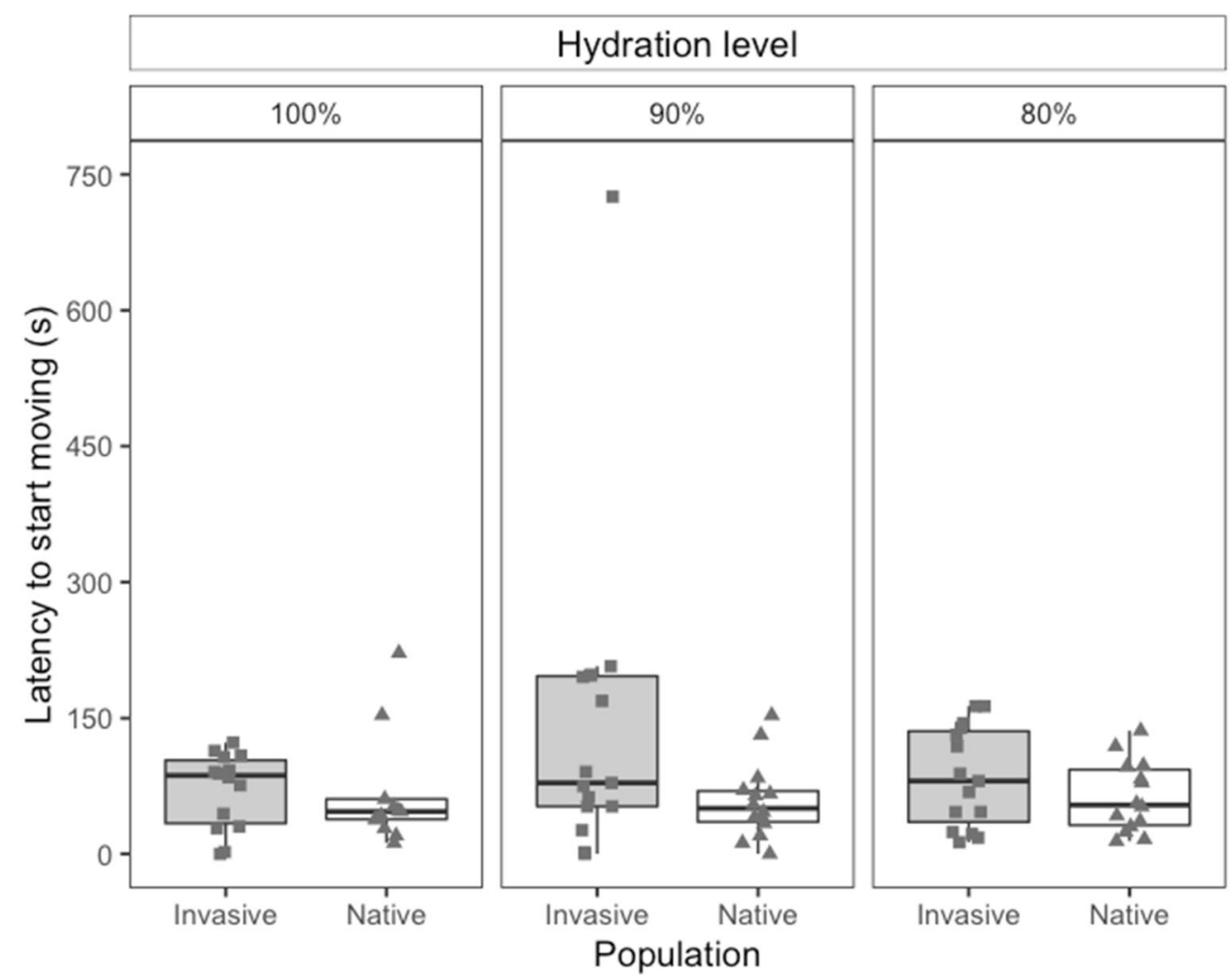


Fig. 2 Time spent hydrating for native and invasive populations at different hydration levels $(80,90$, and $100 \%$ ). Squares (invasive population) and triangles (native population) represent individual observations of the proportion of a trial each animal spent on a water-soaked cotton ball.

Boxplots display the median, 10th, 25th, 75th, and 90th quantiles of observations. Dehydrated animals spend more time on a water source. For both populations, the proportion of hydration time is inversely proportional to hydration levels. Controls (100\% hydrated) spent the least proportion of time directly on top of the water source. Within each condition, no differences between populations was found $(N=41 / 41$ for native, $N=44 / 45$ for invasive; one individual from the invasive population had the last $10 \mathrm{~h}$ of the video corrupted and was removed from this metric)

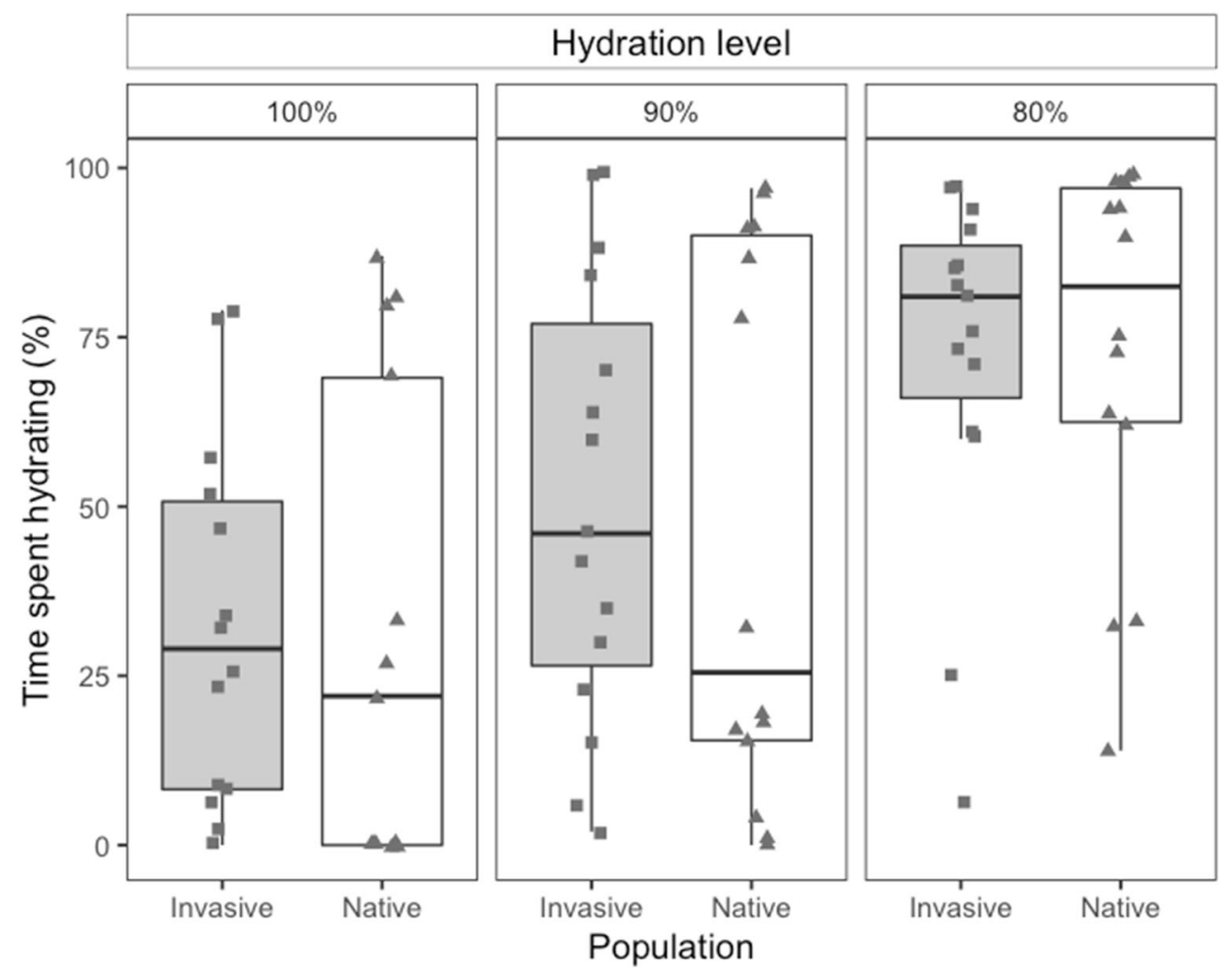

hydration levels, $-0.02-0.10$ ). The total number of attempts to find water between hydration levels in the native population showed no clear pattern in the graphs (CI for native population*hydration levels, 3.0-7.48). Invasive toads hydrated at $90 \%$ made more attempts to find water than native toads at $90 \%$ hydration (Fig. 4, Table 1; CI for invasive
Fig. 3 Time spent within the arm containing the water for native and invasive populations at different hydration levels $(80,90$ and $100 \%$ ). Squares (invasive population) and triangles (native population) represent the proportion of time each animal spent next to a water source, in the arm where the water source was present, but not directly on top of the water-soaked cotton ball. Boxplots display the median, 10th, 25th, 75th, and 90th quantiles of observations. Within each hydration level condition, animals from the invasive population spent more time near a water source than their native counterparts; this trend was mostly prominent within the $90 \%$ hydration condition $(N=41 / 41$ for native, $N=44 / 45$ for invasive; one individual from the invasive population had the last $10 \mathrm{~h}$ of the video corrupted and was removed from this metric)

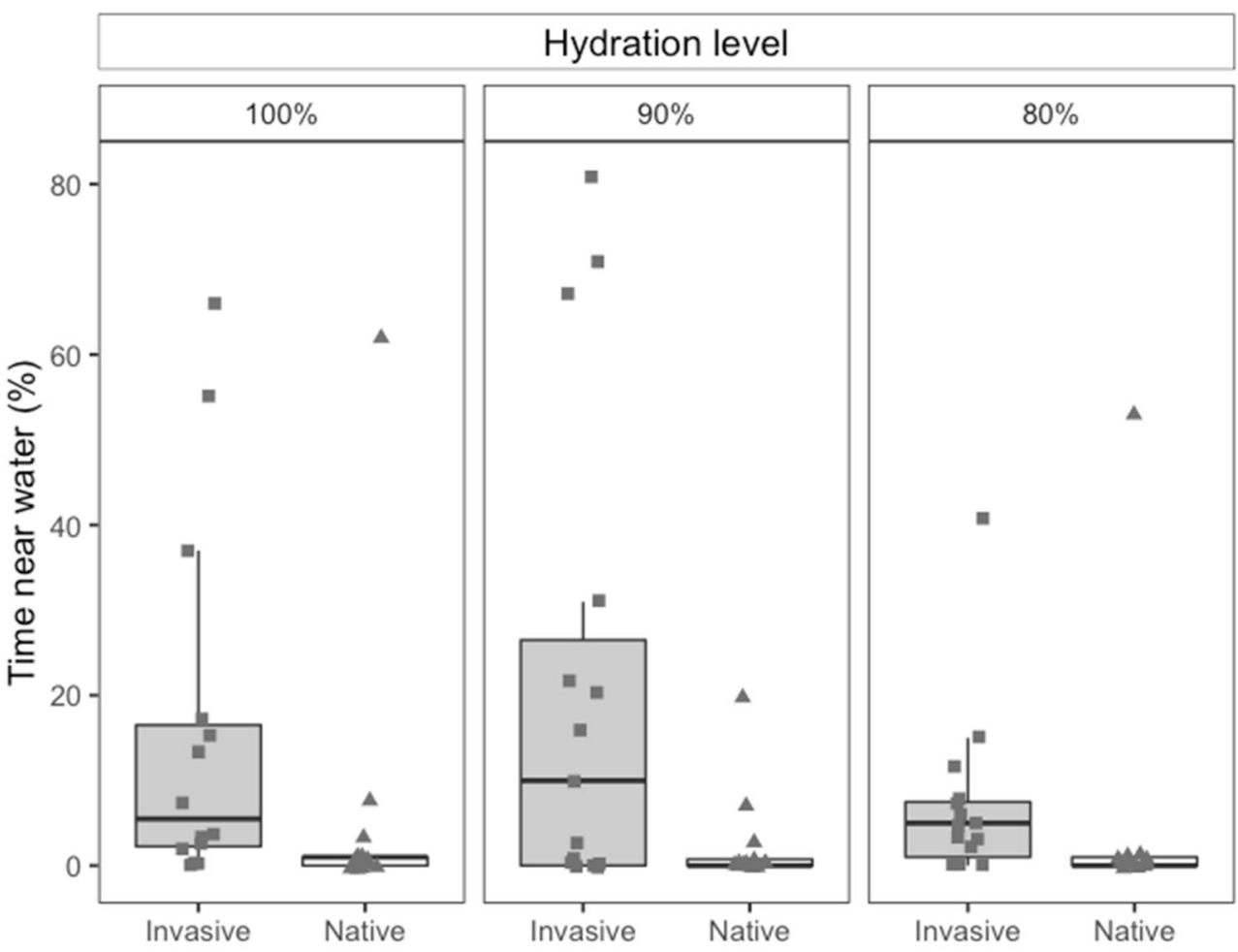

Population 
Fig. 4 Total of attempts to find water at different hydration levels $(80,90$, and $100 \%)$ for native and invasive populations. Squares (invasive population) and triangles (native population) represent the number of times an individual entered an arm of the labyrinth: attempts to find water. This metric was only calculated for trials in which an animal successfully found water $(N=37 /$ 41 for native, $N=44 / 45$ for invasive fulfilled the criteria). Boxplots display the median, 10th, 25th, 75th, and 90th quantiles of observations. Animals at intermediate hydration levels differ in the number of attempts to find water

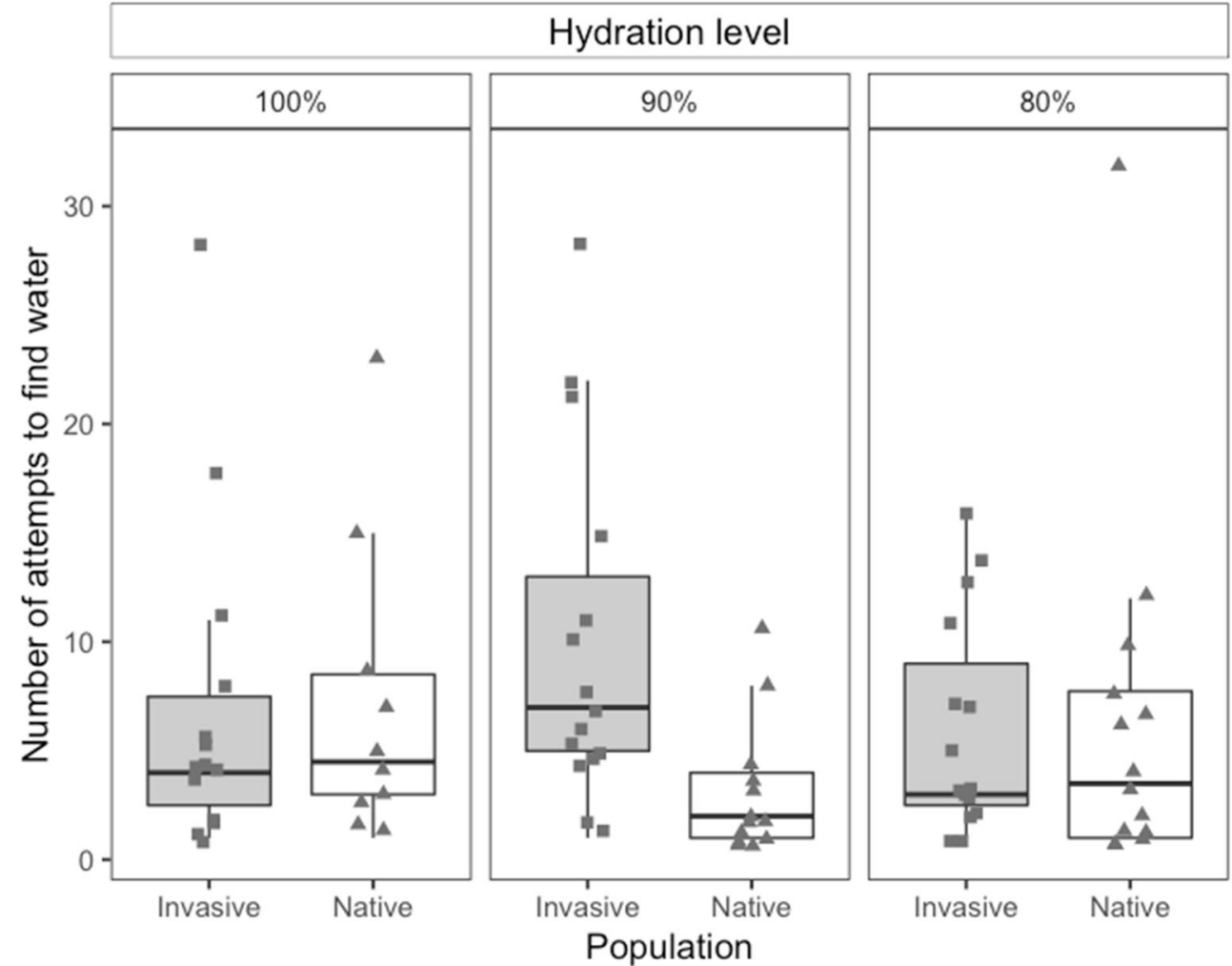

population*hydration levels, 5.6-9.9). The total time spent moving was greater for invasive toads (Fig. 5, Table 1; CI for invasive population, $0.12-0.23$ ). At 90 and $100 \%$ hydration level, time spent not moving was not different between populations (Table 1). At $80 \%$ hydration level, both populations spent more time not moving (Table 1; CI for
Fig. 5 Time spent moving for native and invasive populations at different hydration levels $(80,90$, and $100 \%$ ). Boxplots display the median, 10th, 25th, 75th, and 90th quantiles of observations. Within all hydration levels, animals from the invasive population spent a greater proportion of total trial time active $(N=41 / 41$ for native, $N=44 / 45$ for invasive; one individual from the invasive population had the last $10 \mathrm{~h}$ of the video corrupted and was removed from this metric)

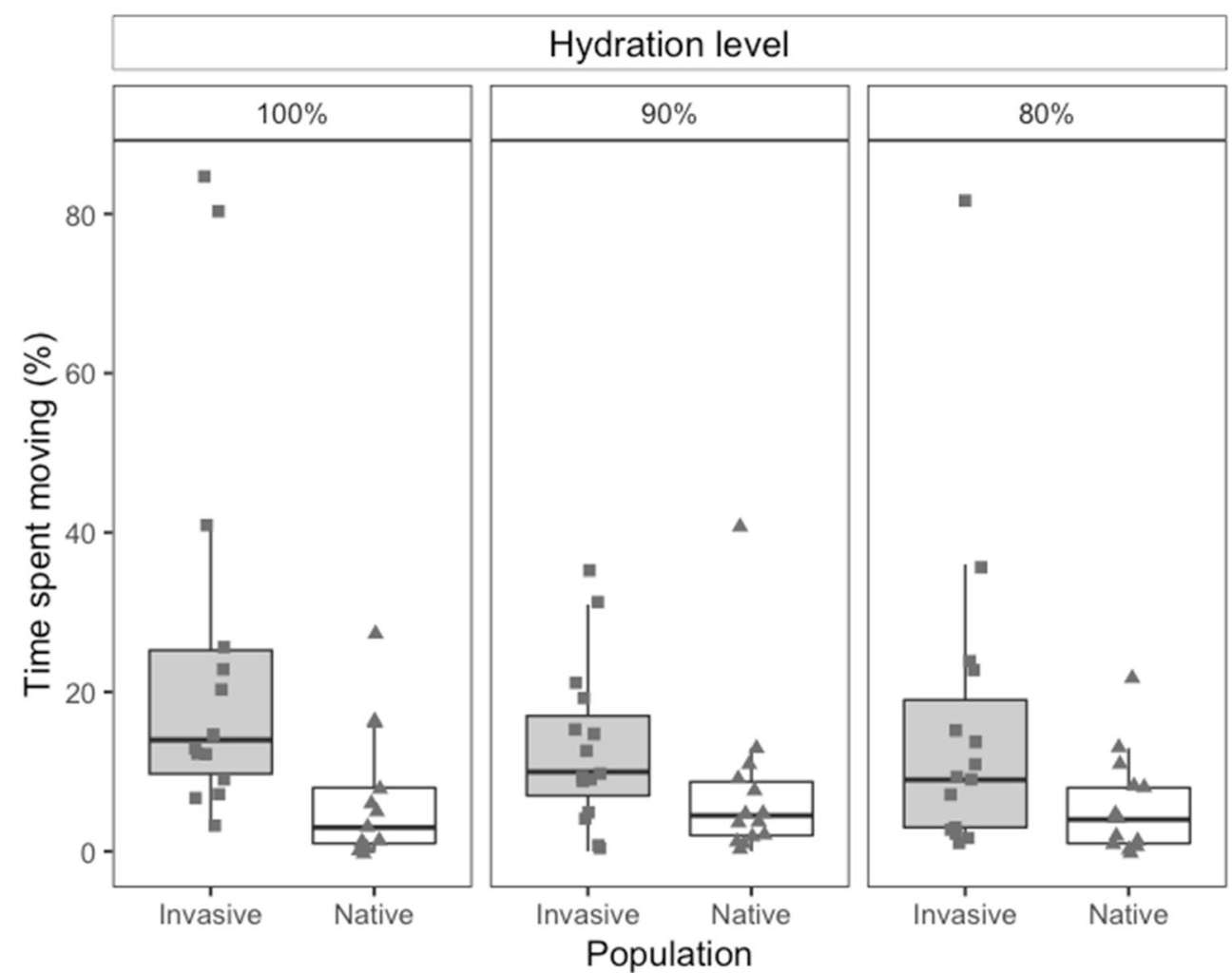


hydration level, $0.29-0.44$ ), but the invasive population had even lower levels of non-activity compared to the native population (Table 1; CI for invasive population, 0.21-0.42).

The PCA of all behavioral traits, at all hydration states, suggests different strategies to finding water between invasive and native populations (Fig. 6). On PC1 (explaining 36.5\% of variation), the total time not moving and time spent within the arm containing the water are strongly related in the invasive population and inversely related to time spent hydrating (Fig. 6). For native toads, the $\mathrm{PC} 1$ explained $35.9 \%$ of variation and total time spent not moving and time spent within the arm containing the water are weakly related, with only total time not moving inversely related to time spent hydrating (Fig. 6). On PC2 (explaining $22.1 \%$ of variation), invasive toads show a close relationship between the number of times that they enter arms (total attempts to find water) and the time taken to find water (Fig. 6), whereas for native toads, PC2 explained $22 \%$ of variation and included the time to find water is more closely related to total time spent moving (Fig. 6).

\section{Water-searching behavior after CORT treatment}

The $200 \mu \mathrm{g}$ of CORT increased the plasma levels $30 \mathrm{~min}$ (mean, $325.5 \mathrm{pg} \mathrm{ml}^{-1}$ ), 45 min (mean, $1461.1 \mathrm{pg} \mathrm{ml}^{-1}$ ), and $1 \mathrm{~h} 45 \mathrm{~min}$ (mean, $503.7 \mathrm{pg} \mathrm{ml}^{-1}$ ) after transdermal application compared to captivity baseline (mean, $312.2 \mathrm{pg} \mathrm{m}^{-1}$ ). The $2000 \mu \mathrm{g}$ of CORT increased the plasma levels $30 \mathrm{~min}$ (mean, $853.1 \mathrm{pg} \mathrm{ml}^{-1}$ ) and $45 \mathrm{~min}$ (mean, $4223.9 \mathrm{pg} \mathrm{ml}^{-1}$ ) after transdermal application compared to captivity baseline (mean, $312.2 \mathrm{pg} \mathrm{ml}^{-1}$ ). The sample from $1 \mathrm{~h} 45 \mathrm{~min}$ after $2000 \mu \mathrm{g}$ CORT was not possible to measure due to technical issues.

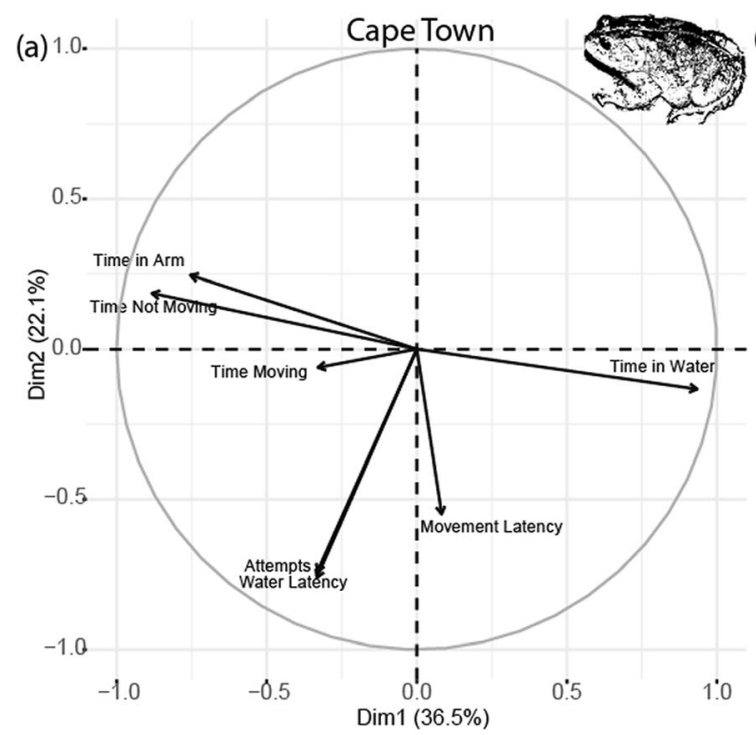

Fig. 6 Principal component analyses for a invasive (Cape Townguttural toad inset) and $\mathbf{b}$ native (Durban-labyrinth apparatus inset) populations of guttural toads, Sclerophrys gutturalis, in relation to
The selected models for water-searching behavior after CORT treatment are displayed in Table 2. CORT treatment affected the success of finding water in fully hydrated individuals. Of individuals treated with 200 and $2000 \mu \mathrm{g}$ of CORT, $80 \%$ and $90 \%$, respectively, found water (Fig. 7). Otherwise, only $40 \%$ of control individuals found water within the $2 \mathrm{~h}\left(X^{2}\right.$ $=6.67, \mathrm{df}=2, P=0.03)$. There was a tendency of individuals having higher latency to move when treated with $2000 \mu \mathrm{g}$ of CORT compared to other groups (Table 2; CI for $200 \mu \mathrm{g}$, 40.0-143; CI for $2000 \mu \mathrm{g}$ treatment, 37.9-221.0). No differences in total attempts to find water, time spent within the arm containing the water, total time spent moving, or total time spent not moving were associated with CORT treatments.

\section{Discussion}

Individuals from the invasive population took longer to start looking for water at the beginning of each trial (increased latency), and once they located the water source, they spent more time in close proximity to it (increased time spent within the arm containing water), compared to toads from the native population. These findings are consistent with the behavior of animals for which water is a scarce resource (Gruber et al. 2017a, b, 2018; Webb et al. 2014), such as in the Mediterranean climate of Cape Town where the guttural toads invaded (see Vimercati et al. 2018). We do not consider these two behavioral traits (i.e., increased latency and time spent near a water source) to be a result of a founder effect as the invasion pathway for this population implies movement of eggs or larvae, but not adults (Measey et al. 2017; Telford et al. 2019). To our surprise, toads

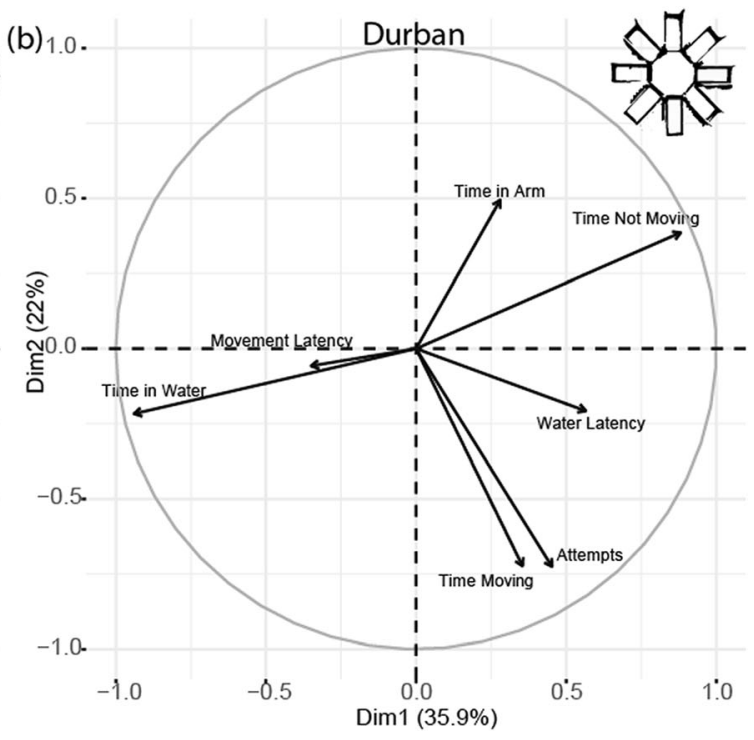

behaviors measured while in a labyrinth searching for water. Data pooled for all hydration levels $(100 \%, 90 \%$, and $80 \%)$. See text for variable definitions 
Fig. 7 Proportion of fully hydrated toads that fail and succeed at finding water after treatments (sesame oil, 200ug and 2000ug of CORT). Acute CORT treatment increases success in finding water in guttural toads, Sclerophrys gutturalis

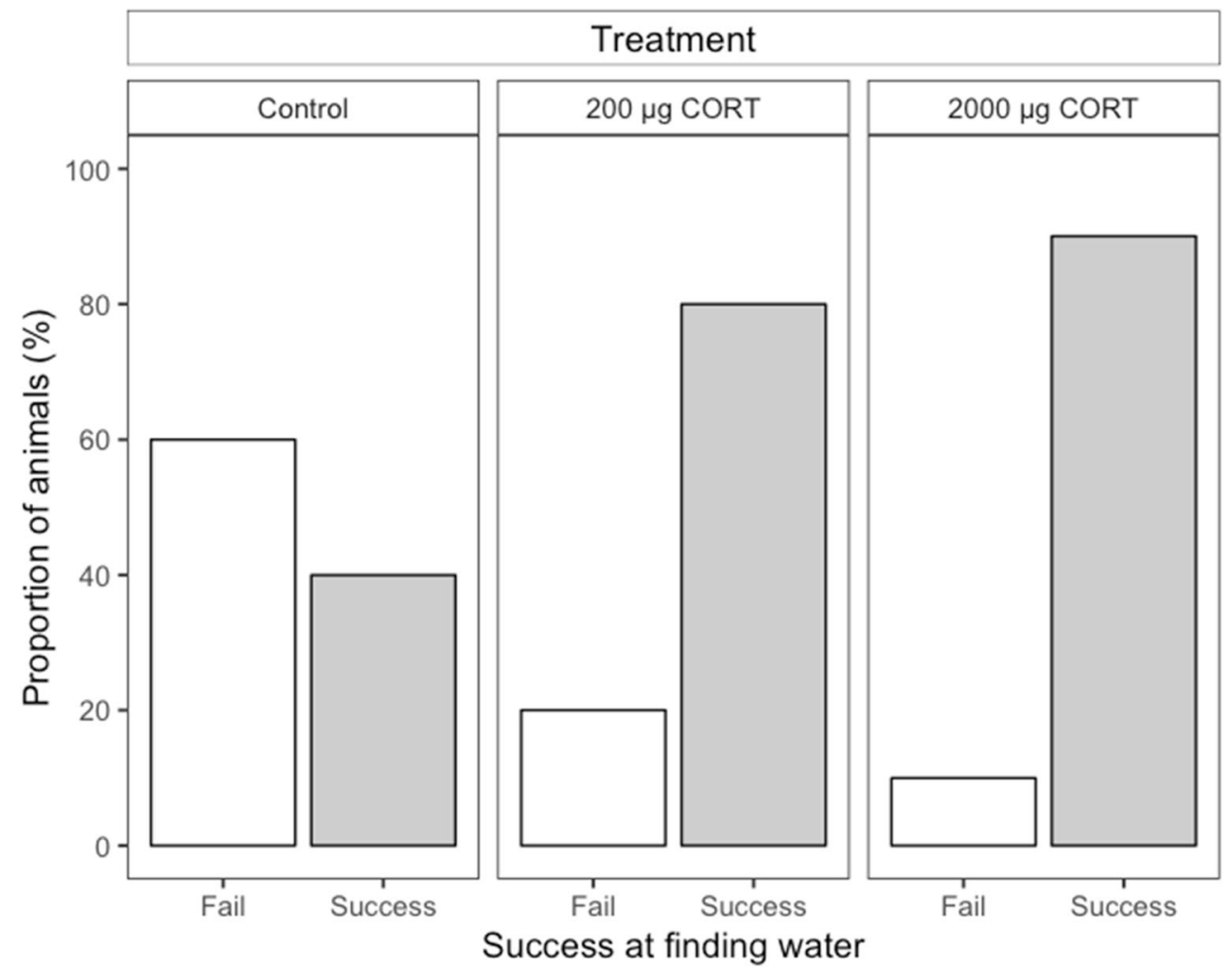

from the invasive population did not show a decreased time to find water or a lower number of attempts to find water, as originally outlined in the "water-finding hypothesis" by CruzPiedrahita et al. (2018). Nevertheless, we do consider that the behavioral characteristics observed in the invasive guttural toad population do act to increase their water-conservation and rehydration abilities. A longer time spent in a water-conservation posture prior to moving and remaining closer to the water source after rehydration will impact their general water balance and have the potential to enhance an individual's survival. In this way, we assert that these results are in accordance with the overall concept of the "water-finding hypothesis" (CruzPiedrahita et al. 2018) and further contribute to the behavioral repertoire encompassed by it. Contrary to what we expected, we did not find evidence that these behaviors were exaggerated for toads as the level of dehydration increases. Although dehydration is known to have profound effects on locomotor performance (Titon Jr and Gomes 2017; Vimercati et al. 2018), it did not cause significant changes in water-finding behaviors in the current study. Nevertheless, artificially increasing CORT, mirroring levels to that seen during dehydration stress (Barsotti et al. 2019), did increase overall water-finding behavior in these toads.

Time spent absorbing water was inversely related to hydration state, since toads that were further dehydrated required more time to recover their optimal hydric state, but no differences were observed among populations. For cane toads with
80 years of invasion history, there are differences in water uptake rates between populations from xeric and mesic areas (Tingley et al. 2012). The lack of differences between guttural toad populations regarding the time animals spent hydrating might be attributed to the fact that the species has only 20 years of invasion history in Cape Town. Vimercati et al. (2018) also did not find differences in rates of water uptake or water loss. This might indicate that these populations do not differ in terms of thickness of the integument or enhanced blood vessel supply and aquaporin expression in the pelvic patch structure (Lillywhite 2006; Ogushi et al. 2010). Instead, the invasive population of guttural toad likely overcomes the challenges of a novel xeric environment through behavioral modification.

Behaviors specific to the invasive population may provide advantages to individuals encountering novel environments. During both the initial inertia (latency to move) and the posthydration period, we observed toads resting in the waterconserving posture (c.f., Prates and Navas 2009), a behavior already noted when these toads are dehydrated (Vimercati et al. 2018). This posture allows the individual to avoid higher rates of water loss by tucking in their limbs to shield their ventral surface from exposure (Heatwole et al. 1969). This specific stance coupled with a delay in initiation of water-searching behavior may confer an advantage in terms of water balance, as they can assess air humidity from novel surroundings (Grubb 1973; Sinsch 1990; Reshetnikov 1998) to track the odor of 
water (Grubb 1976). In doing so, the toads can assess their surroundings for humidity while minimizing water loss and thus maximize their hydration levels. It is possible that invasive toads possess adaptive personalities (i.e., repeatable behavioral traits over time; Kelleher et al. 2018) regarding water-searching behavior compared to native toads. When personalities, or behavioral syndromes (i.e., correlated behavioral traits; Kelleher et al. 2018), are particularly successful in challenging environments, this may lead to them quickly becoming fixed in a population. We suggest further research examining the relationship and repeatability of these combinations of behavioral traits (i.e., water-conservation posture and the olfactory orientation: Grubb 1973, 1976; Prates and Navas 2009) in native and invasive populations. This may determine if they represent independent fixed water-finding traits and their association with habitat type and invasion status.

After a water source has been found, and following hydration, toads from the invasive population in Cape Town spent considerably more time within the labyrinth arm containing water. This trait was also correlated to the toads' time spent not moving. Interestingly, for the native population, time spent not moving was correlated to the time toads spent hydrating. This suggests that after toads from the invasive population found a critical resource, they were more prone to remain close to it, when compared to conspecifics from the native range. Similar patterns have been seen in cane toads in Australia, which remained close to a food source at night and over a period of weeks (Silvester et al. 2017, 2018). Furthermore, when the surrounding landscape is dry, cane toads appear unwilling to disperse away from sources of moisture (Brown et al. 2011). Our current findings cannot directly indicate an increase in sedentary behavior within the invasive guttural toad population, as seen by cane toads in Australia (Brown et al. 2011; Silvester et al. 2018); however, maintaining a close position to an important resource is a critical behavioral shift to cope with the challenges of invasion (Gruber et al. 2017b). We suggest that further research use in situ spatial ecology of invasive and native populations to further test this hypothesis by examining shifts in dispersal rates and movement patterns. Anecdotal observations from the invasive Cape Town population have noted that their spread in the region is associated with the presence of manicured gardens (e.g., water features and sprinkler systems), suggesting that this behavior is occurring even at the population level. Considering that amphibians are highly susceptible to the deleterious effects of dehydration (Titon Jr and Gomes 2017; Barsotti et al. 2019) and evolved multiple strategies to maintain water balance (McClanahan and Baldwin 1969; Prates and Navas 2009), the behavioral strategy of staying close to a known water source is considered a very successful attribute to improve fitness and invasion success (Sol et al. 2002).

The invasive toads hydrated at $90 \%$ made more attempts to find water than toads from the same population at other hydration levels. This might indicate that at $90 \%$ hydration, individuals can afford an erratic search strategy that increases exposure of their ventral area and consequently higher rates of water loss (Heatwole et al. 1969). The behavioral strategy of performing less attempts to look for water at $80 \%$ hydration level may have been the result of an innate strategy to reduce evaporative water loss that is triggered after a particular dehydration threshold is reached. The number of attempts to find water showed no differences between hydration levels in the native population, a pattern that might result from the absence of directional selection in water-searching behavior due to the high humidity and water availability in their origin population (Durban, South Africa; Vimercati et al. 2018; Telford et al. 2019). Additionally, the time spent moving was significantly greater for invasive toads. The behavioral shift towards dispersal at the range edge in invasive anurans has already been observed (Lindström et al. 2013; Gruber et al. 2017b; Courant et al. 2019), and the investment in high locomotion rates in invasive anurans could contribute to higher dispersal rates resulting in higher invasion success (Courant et al. 2017). Additionally, our data suggest that invasive toads display different behavioral strategies to find water when compared to the native population, (1) they appear to make more attempts to find water while native toads simply keep moving, and (2) once rehydrated, invasive toads stayed close to the water, while native toads continued to move around the labyrinth. This set of behavioral strategies to find water that we describe is suggestive of different behavioral syndromes within certain populations, but this remains to be tested with a larger number of individuals and with repeated measures on each individual at the same hydration state.

We also found that artificially increasing CORT, to similar levels observed when toads are dehydrated, increased waterfinding behavior (i.e., the CORT treatment increased the success of finding water). In mammals, administration of GC increases water and sodium excretion, promoting extracellular volume contraction and increasing, indirectly, water drinking (Thunhorst et al. 2007). In addition, GC potentiates ANG IImediated drinking behavior through GC type II receptors in the brain (Ganesan and Summers 1989; Sumners et al. 1991). In terrestrial toads, intraperitoneal and intracerebroventricular injections of ANG II induce water reabsorption (Propper and Johnson 1994; Propper et al. 1995), and ANG II-injected individuals also showed shorter latency to find water and increased time spent in water than those in control treatments (Viborg and Rosenkilde 2011). In this way, CORT might increase motivation to find water in toads both by promoting central brain effects and volume contraction. The fast effects of the treatment on water search behavior in the toads can also be explained by non-genomic CORT effects. ANG II and GC modulate the synthesis and secretion of neurohypophyseal hormones, particularly oxytocin, in rats exposed to different experimental conditions of altered fluid volume and tonicity (Ruginsk et al. 
2009). The underlying mechanisms by which CORT administration results in rapid behavioral changes observed in our toads remain to be tested. Animals treated with $2000 \mu \mathrm{g}$ of CORT showed a tendency towards higher latency to start moving in the labyrinth. The effects of CORT elevation and acute stressors on behavior are contradictory, while CORT increases locomotion in amphibians and fishes (Crespi and Denver 2004; Lowry and Moore 2006), handling stress decreases feeding and locomotor activity in amphibians (Ricciardella et al. 2010; Bliley and Woodley 2012). Overall, our results might indicate that the elevation of CORT in response to dehydration as a stressor represents an important modulator of physiological and behavioral homeostatic responses, including stimulated watersearching behavior.

Our results reinforce the level to which invasive guttural toads rely on the presence of garden ponds in a peri-urban area, which otherwise would be nearly devoid of standing water during the summer months (Vimercati et al. 2017). Davies et al. (2019) stressed that without the availability of artificial water bodies, the painted reed frog (Hyperolius marmoratus) would not have been able to invade the same Mediterranean climate. Similarly, Brusch et al. (2019) emphasized that the cane toad's rapid spread across large areas of arid Australia would not have been possible without the farm impoundments that cover the region. These findings underline the importance of monitoring artificial impoundments in arid areas for invasions. While we demonstrated that behavioral traits are important for adult guttural toads, other life-history stages have even greater requirements for access to water. For example, postmetamorphic toads (Rhinella granulosa) have a higher thermal tolerance and a keen ability to detect and uptake water (Navas et al. 2007). Behavioral differences relating to hydric condition among native and invasive populations in different life-history stages and across ontogeny are a fascinating avenue of research that should be explored further (Wilson and Krause 2012a). It is our hope that this research will not only prompt further investigation in this topic from theoretical and scientific standpoints but also provide insights that can be used to bolster the management of invasive species.

Our study represents an important step in developing our understanding of the relationship between water-searching behavior and physiology, as well as how this can provide invasive amphibians an advantage when colonizing xeric habitats. The capability of displaying optimal behavior in a challenging habitat can improve an individual's survival and thus invasion success (Smith and Blumstein 2008; Chapple et al. 2012). It is important to note, however, the limitations of this study, as they can guide future research and reduce misinterpretation. We acknowledge that our comparison involved only a single native and invasive population, and as such, we cannot tease apart direct population to population effects from invasive to native effects. Yet, invasive toads show several physiological and behavioral traits that differed from the native range
(Vimercati et al. 2018, 2019; present study) and also mirror what has been seen in other amphibians invading arid habitats (Gruber et al. 2017a, b, 2018; Webb et al. 2014). Thus, the general behavioral trend we observed might be due to the environmental conditions the invasive toads experienced (Garland Jr and Adolph 1994; Wilson and Krause 2012b; Kelleher et al. 2018). Furthermore, studies on this topic should examine repeatability in these behavioral traits, which should be conducted in native populations across eastern sub-Saharan Africa, as well as including additional invasive populations outside of South Africa (i.e., Mauritius and Réunion; Telford et al. 2019). Research along these lines would take the important next step in determining if these traits are fixed, temporally limited, and/or positively or negatively associated with other characteristics (Sih et al. 2004; Careau and Wilson 2017; Kelleher et al. 2018). Moreover, the link between CORT and success in finding water shows that this hormone can modulate behavioral responses. Elucidating the physiological mechanisms that mediated those changes in water-searching behavioral can improve our understanding of how individual's phenotype is modulated by CORT during an environmental challenge.

Acknowledgments We would like to thank Jonathan Bell for the help with fieldwork in Cape Town; Giovanni Vimercati for the advice on guttural toads; Carlos A. Navas, Braz Titon Jr., Danielle Dillon, Julia Riley, and the anonymous reviewers for their comments on the manuscript. Hannes van Wyk, Christy Momberg, and Erica Nortje helped with access to facilities and administration at Stellenbosch University.

Authors' contributions CBM, FRG, and JM conceived the ideas and designed methodology; CBM, AMGB, CW, and JBG collected animals; $\mathrm{CBM}, \mathrm{AMGB}$, and JBG carried out the experiment; CBM and YS analyzed the videos; CBM analyzed the data; and CBM, JBG, FRG, and JM contributed to the writing of the manuscript.

Funding information $\mathrm{CBM}$ and AMGB received a FAPESP bursary (2018/00406-0 and 2018/23661-6, respectively) to visit South Africa. JM received a grant from Centre for Partnerships and Internationalisation at SU for supporting bilateral collaboration activities with USP. JM, CW, and JBG are funded by the DSI-NRF Centre of Excellence for Invasion Biology. FRG is a research fellow from the Brazilian CNPq (Conselho Nacional de Desenvolvimento Científico e Tecnológico from Brazil \#302308/2016-4 and lead a FAPESP grant 2014/16320-7).

Data Availability Data is available at Pangaea (PDI-21680 - Behavioral traits to find water in anurans), https://doi.org/10.1594/PANGAEA. 906934

Code availability See supplementary material for R script.

\section{Compliance with ethical standards}

Conflict of interests The authors declare that they have no competing interests.

Ethical approval Ethics clearance for research on captive toads was obtained from Stellenbosch University Animal Ethics Committee 
(protocol number ACU-2019-8839) that follows the South African National Standard for the Care and Use of Animals for Scientific Purpose, and from the Comissão de Ética no Uso de Animais (CEUA: 249/2016) of Instituto de Biociências da Universidade de São Paulo that follows the ARRIVE Guidelines (Kilkenny et al. 2010). All applicable national and international guidelines for the use of animals were followed. Permits for toad collections in the native area (Durban: KZN Wildlife permit number: OP 4353/2018) and invasive area (Cape Town: CapeNature CN44-31-7259) came from South African provincial conservation authorities.

Consent to participate (include appropriate statements) Not applicable

Consent for publication All authors gave final approval for publication.

\section{References}

Akaike H (1974) A new look at the statistical model identification. IEEE T Automat Contr 19:716-723

Anderson RCO, Andrade DV (2017) Trading heat and hops for water: dehydration effects on locomotor performance, thermal limits, and thermoregulatory behavior of a terrestrial toad. Ecol Evol 7:90669075

Arnold TW (2010) Uninformative parameters and model selection using Akaike's information criterion. J Wildl Manag 74(6):1175-1178

Assis VR, Titon SCM, Barsotti AMG, Titon B Jr, Gomes FR (2015) Effects of acute restraint stress, prolonged captivity stress and transdermal corticosterone application on immunocompetence and plasma levels of corticosterone on the cururu toad (Rhinella icterica). PLoS One 10:e0121005

Barsotti AMG, Titon B Jr, Titon SCM, Gomes FR (2019) Dehydration as a stressor in toads (Rhinella ornata). J Exp Zool A 331:168-174

Bates D, Maechler M, Bolker B, Walker S (2015) Fitting linear mixedeffects models using lme4. J Stat Softw 67:1-48

Bentley PJ, Schmidt-Nielsen K (1966) Cutaneous water loss in reptiles. Science 151:1547-1549

Blackburn TM, Pyšek P, Bacher S, Carlton JT, Duncan RP, Jarošík V, Wilson JRU, Richardson DM (2011) A proposed unified framework for biological invasions. Trends Ecol Evol 26:333-339

Bliley JM, Woodley SK (2012) The effects of repeated handling and corticosterone treatment on behavior in an amphibian (Ocoee salamander: Desmognathus ocoee). Physiol Behav 105:1132-1139

Bolker B (2009) bbmle: Tools for general maximum likelihood estimation, $\mathrm{R}$ package version 0.9.3, http://CRAN.R-project.org/package $=$ bbmle

Brown G, Kelehear C, Shine R (2011) Effects of seasonal aridity on the ecology and behaviour of invasive cane toads in the Australian wetdry tropics. Funct Ecol 25:1339-1347

Brusch GA, Christian K, Brown GP, Shine R, DeNardo DF (2019) Cane toads (Rhinella marina) rely on water access, not drought tolerance, to invade xeric Australian environments. Oecologia 189:307-316

Bucciarelli GM, Blaustein AR, Garcia TS, Kats LB (2014) Invasion complexities: the diverse impacts of nonnative species on amphibians. Copeia 4:611-632

Burnham KP, Anderson DR (2002) Model selection and multimodel inference: a practical information-theoretic approach. Springer, New York

Capinha C, Seebens H, Cassey P, García Díaz P, Lenzner B, Mang T, Winter M (2017) Diversity, biogeography and the global flows of alien amphibians and reptiles. Divers Distrib 23:1313-1322

Careau V, Wilson RS (2017) Of uberfleas and krakens: detecting tradeoffs using mixed models. Integr Comp Biol 57:362-371
Carere C, Gherardi F (2013) Animal personalities matter for biological invasions. Trends Ecol Evol 28:5-6

Chapple DG, Simmonds SM, Wong BB (2012) Can behavioral and personality traits influence the success of unintentional species introductions? Trends Ecol Evol 27:57-64

Child T, Phillips BL, Shine R (2009) Does desiccation risk drive the distribution of juvenile cane toads (Bufo marinus) in tropical Australia? J Trop Ecol 25:193-200

Courant J, Secondi J, Bezeiriat V, Herrel A (2017) Resources allocated to reproduction decrease at the range edge of an expanding population of an invasive amphibian. Biol J Linn Soc 122:157-165

Courant J, Secondi J, Guillemet L, Volette E, Herrel A (2019) Rapid changes in dispersal on a small spatial scale at the range edge of an expanding population. Evol Ecol 33:599-612

Crespi EJ, Denver RJ (2004) Ontogeny of corticotropin-releasing factor effects on locomotion and foraging in the Western spadefoot toad (Spea hammondii). Horm Behav 46:399-410

Cruz-Piedrahita C, Navas CA, Crawford AJ (2018) Life on the edge: a comparative study of ecophysiological adaptations of frogs to tropical semiarid environments. Physiol Biochem Zool 91:740-756

Davies SJ, Hill MP, McGeoch MA, Clusella-Trullas S (2019) Niche shift and resource supplementation facilitate an amphibian range expansion. Divers Distrib 25:154-165

De Villiers A (2006) Bufo gutturalis Power, 1927. Guttural toad. Introduced population. Afr Herpetol News 40:28-29

Duncan RP, Williams PA (2002) Ecology: Darwin's naturalization hypothesis challenged. Nature 417:608-609

Friard O, Gamba M (2016) BORIS: a free, versatile open-source eventlogging software for video/audio coding and live observations. Methods Ecol Evol 7:1324-1330

Ganesan R, Summers C (1989) Glucocorticoids potentiate the dipsogenic action of angiotensin II. Brain Res 499:121-130

Garland T Jr, Adolph SC (1994) Why not to do two-species comparative studies: limitations on inferring adaptation. Physiol Zool 67:797828

Grubb JC (1973) Olfactory orientation in Bufo woodhousei fowleri, Pseudacris clarki and Pseudacris streckeri. Anim Behav 21:726732

Grubb JC (1976) Maze orientation by Mexican toads, Bufo valliceps (Amphibia, Anura, Bufonidae), using olfactory and configurational cues. J Herpetol 10:97-104

Gruber J, Brown G, Whiting MJ, Shine R (2017a) Geographic divergence in dispersal-related behaviour in cane toads from range-front versus range-core populations in Australia. Behav Ecol Sociobiol 71:38

Gruber J, Brown G, Whiting MJ, Shine R (2017b) Is the behavioural divergence between range-core and range-edge populations of cane toads (Rhinella marina) due to evolutionary change or developmental plasticity? R Soc Open Sci 4:170-789

Gruber J, Brown G, Whiting MJ, Shine R (2018) Behavioural divergence during biological invasions: a study of cane toads (Rhinella marina) from contrasting environments in Hawai'i. R Soc Open Sci 5:180 197

Heatwole H, Torres F, Blassini de Austin S, Heatwole A (1969) Studies on anuran water balance. I. Dynamics of evaporative water loss by the coquí, Eleutherodactylus portoricensis. Comp Biochem Physiol 28:245-269

Herrel A, van der Meijden A (2014) An analysis of the live reptile and amphibian trade in the USA compared to the global trade in endangered species. Herpetol J 24:103-110

Hillman SS (1982) The effects of in vivo and in vitro hyperosmolality on skeletal muscle performance in the amphibians Rana pipiens and Scaphiopus couchii. Comp Biochem Physiol A 73:709-712

Hillyard SD (1999) Behavioral, molecular and integrative mechanisms of amphibian osmoregulation. J Exp Zool 283:662-674

Holway DA, Suarez AV (1999) Animal behavior: an essential component of invasion biology. Trends Ecol Evol 14:328-330 
Jessop TS, Webb J, Dempster T, Feit B, Letnic M (2018) Interactions between corticosterone phenotype, environmental stressor pervasiveness and irruptive movement-related survival in the cane toad. J Exp Biol 221:jeb187930

Jørgensen CB (1997) 200 years of amphibian water economy: from Robert Townsend to the present. Biol Rev 72:153-237

Kelleher SR, Silla AJ, Byrne PG (2018) Animal personality and behavioral syndromes in amphibians: a review of the evidence, experimental approaches, and implications for conservation. Behav Ecol Sociobiol 72:79

Kilkenny C, Browne WJ, Cuthill IC, Emerson M, Altman DG (2010) The ARRIVE guidelines checklist animal research: reporting in vivo experiments. Br J Pharmacol 8:8-9

Kraus F (2008) Alien reptiles and amphibians: a scientific compendium and analysis, vol 4. Springer Science \& Business Media, Berlin

Kueffer C, Pyšek P, Richardson DM (2013) Integrative invasion science: model systems, multi-site studies, focused meta-analysis and invasion syndromes. New Phytol 200:615-633

Lenth RV (2016) Least-squares means: the R package 1smeans. J Stat Softw 69(1):1-33

Lever C (2001) The Cane Toad. The history and ecology of a successful colonist. Westbury Academic Publishing, West Yorkshire

Lillywhite HB (2006) Water relations of tetrapod integument. J Exp Biol 209:202-226

Lindström T, Brown GP, Sisson SA, Phillips BL, Shine R (2013) Rapid shifts in dispersal behavior on an expanding range edge. P Natl Acad Sci USA 110:13452-13456

Louppe V, Courant J, Herrel A (2017) Differences in mobility at the range edge of an expanding invasive population of Xenopus laevis in the west of France. J Exp Biol 220:278-283

Lowry CA, Moore FL (2006) Regulation of behavioral responses by corticotropin-releasing factor. Gen Comp Endocrinol 146:19-27

Luke SG (2017) Evaluating significance in linear mixed-effects models in R. Behav Res Methods 49:1494-1502

Madelaire CB, Cassettari BO, Gomes FR (2019) Immunomodulation by testosterone and corticosterone in toads: Experimental evidences from transdermal application. Gen Comp Endocrinol 273:227-235

McClanahan L, Baldwin R (1969) Rate of water uptake through the integument of the desert toad, Bufo punctatus. Comp Biochem Physiol A 28:381-389

Measey J, Davies S, Vimercati G, Rebelo A, Schmidt W, Turner AA (2017) Invasive amphibians in southern Africa: a review of invasion pathways. Bothalia 47:1-12

Mendonça MT, Chernetsby SD, Nester KE, Gardner GL (1996) Effects of sex steroids on sexual behavior in the big brown bat, Eptesicus fuscus. Horm Behav 30:153-161

Moore FR, Gatten RE Jr (1989) Locomotor performance of hydrated, dehydrated and osmotically stressed anuran amphibians. Herpetologica 45:101-110

Navas CA, Antoniazzi MM, Carvalho JE, Suzuki H, Jared C (2007) Physiological basis for diurnal activity in dispersing juvenile Bufo granulosus in the Caatinga, a Brazilian semi-Arid environment. Comp Biochem Physiol A 147:647-657

Novoa A, Richardson DM, Pyšek P, Meyerson LA, Bacher S, Canavan S, Catford JA, Čuda J, Essl F, Foxcroft LC, Genovesi P, Hirsch H, Hui C, Jackson MC, Kueffer C, le Roux JJ, Measey J, Mohanty NP, Moodley D, Müller-Schärer H, Packer JG, Pergl J, Robinson TB, Saul WC, Shackleton RT, Visser V, Weyl OLF, Yannelli FA, Wilson JRU (2020) Invasion syndromes: a systematic approach for predicting biological invasions and facilitating effective management. Biol Invasions 22:1801-1820

Nunes AL, Fill JM, Davies SJ, Louw M, Rebelo AD, Thorp CJ, Measey J (2019) A global meta-analysis of the ecological impacts of alien species on native amphibians. Proc R Soc B 286:20182528

Ogushi Y, Kitagawa D, Hasegawa T, Suzuki M, Tanaka S (2010) Correlation between aquaporin and water permeability in response to vasotocin, hydrin and $\beta$-adrenergic effectors in the ventral pelvic skin of the tree frog Hyla japonica. J Exp Biol 213:288-294

Prates I, Navas CA (2009) Cutaneous resistance to evaporative water loss in Brazilian Rhinella (Anura: Bufonidae) from contrasting environments. Copeia 2009:618-622

Propper CR, Johnson WE (1994) Angiotensin II induces water absorption behavior in two species of desert anurans. Horm Behav 28:41-52

Propper CR, Hillyard SD, Johnson WE (1995) Central angiotensin II induces thirst-related responses in an amphibian. Horm Behav 28: 74-84

Reshetnikov AN (1998) Searching for water by the common treefrog (Hyla arborea) and the green toad (Bufo viridis): the perception of odours or air humidity? In: Kuzmin SL (ed) Advances in Amphibian Research in the Former. Sofia, Moscow, pp 105-112

Ricciardella LF, Bliley JM, Feth CC, Woodley SK (2010) Acute stressors increase plasma corticosterone and decrease locomotor activity in a terrestrial salamander (Desmognathus ochrophaeus). Physiol Behav $101: 81-86$

Romero LM, Reed JM (2005) Collecting baseline corticosterone samples in the field: is under 3 min good enough? Comp Biochem Physiol A 140:73-79

Ruginsk SG, Lopes da Silva A, Ventura RR, Elias LLK (2009) Central actions of glucocorticoids in the control of body fluid homeostasis. Braz J Med Biol Res 42:61-67

Sapolsky RM, Romero LM, Muck AU (2000) How do glucocorticoids influence stress responses? Integrating permissive, suppressive, stimulatory, and preparative actions. Endocr Rev 21:55-89

Schwarzkopf L, Alford RA (1996) Desiccation and shelter-site use in a tropical amphibian: comparing toads with physical models. Funct Ecol 10:193-200

Seebacher F, Alford RA (2002) Shelter microhabitats determine body temperature and dehydration rates of a terrestrial amphibian (Bufo marinus). J Herpetol 36:69-75

Seebens H, Blackburn TM, Dyer EE, Genovesi P, Hulme PE, Jeschke JM (2018) Global rise in emerging alien species results from increased accessibility of new source pools. P Natl Acad Sci USA 115:E2264 E2273

Sih A, Bell A, Johnson JC (2004) Behavioral syndromes: an ecological and evolutionary overview. Trends Ecol Evol 19:372-378

Silvester R, Shine R, Oldroyd B, Greenlees M (2017) The ecological impact of commercial beehives on invasive cane toads (Rhinella marina) in eastern Australia. Biol Invasions 19:1097-1106

Silvester R, Greenlees M, Shine R, Oldroyd B (2018) Behavioural tactics used by invasive cane toads (Rhinella marina) to exploit apiaries in Australia. Austral Ecol 44:237-244

Sinsch U (1990) Migration and orientation in anuran amphibians. Ethol Ecol Evol 2:65-79

Smith BR, Blumstein DT (2008) Fitness consequences of personality: a meta-analysis. Behav Ecol 19:448-455

Sol D, Timmermans S, Lefebvre L (2002) Behavioural flexibility and invasion success in birds. Anim Behav 63:495-502

Sumners C, Gault TR, Fregly MJ (1991) Potentiation of angiotensin IIinduced drinking by glucocorticoids is a specific glucocorticoid Type II receptor (GR)-mediated event. Brain Res 552:283-290

Takei Y (2000) Comparative physiology of body fluid regulation in vertebrates with special reference to thirst regulation. Jpn J Physiol 50: $171-186$

Telford N, Channing A, Measey J (2019) Origin of invasive populations of the Guttural toad (Sclerophrys gutturalis) on Reunion and Mauritius Islands and in Constantia, South Africa. Herpetol Conserv Biol 14:380-392

Thunhorst RL, Beltz TG, Johnson AK (2007) Glucocorticoids increase salt appetite by promoting water and sodium excretion. Am J Physiol Reg I 293:R1444-R1451 
Tingley R, Shine R (2011) Desiccation risk drives the spatial ecology of an invasive anuran (Rhinella marina) in the Australian semi-desert. PLoS One 6:e25979

Tingley R, Greenlees MJ, Shine R (2012) Hydric balance and locomotor performance of an anuran (Rhinella marina) invading the Australian arid zone. Oikos 121:1959-1965

Titon B Jr, Gomes FR (2017) Associations of water balance and thermal sensitivity of toads with macroclimatic characteristics of geographical distribution. Comp Biochem Physiol 208:54-60

Titon B Jr, Navas CA, Jim J, Gomes FR (2010) Water balance and locomotor performance in three species of neotropical toads that differ in geographical distribution. Comp Biochem Physiol 156: $129-135$

Toledo RC, Jared C (1993) Cutaneous adaptations to water balance in amphibians. Comp Biochem Physiol 105:593-608

Tylan C, Camacho K, French SS, Graham SP, Herr MW, Jones J, McCormick GL, O'Brien MA, Tennessen JB, Thawley CJ, Webb A, Langkilde T (2020) Obtaining plasma to measure baseline corticosterone concentrations in reptiles: how quick is quick enough? Gen Comp Endocrinol 287:113324

van Wilgen NJ, Gillespie MS, Richardson DM, Measey J (2018) A taxonomically and geographically constrained information base limits non-native reptile and amphibian risk assessment: a systematic review. PeerJ 6:e5850

Viborg AL, Rosenkilde P (2011) Angiotensin II elicits water seeking behavior and the water absorption response in the toad Bufo bufo. Horm Behav 39:225-231
Vimercati G, Davies SJ, Hui C, Measey J (2017) Integrating age structured and landscape resistance models to disentangle invasion dynamics of a pond-breeding anuran. Ecol Model 356:104-116

Vimercati G, Davies SJ, Measey J (2018) Rapid adaptive response to a Mediterranean environment reduces phenotypic mismatch in a recent amphibian invader. J Exp Biol 221:jeb174797

Vimercati G, Davies S, Measey J (2019) Invasive toads adopt marked capital breeding when introduced to a cooler, more seasonal environment. Biol J Linn Soc (published online, https://doi.org/10.1093/ biolinnean/blz119)

Walls SC, Gabor CR (2019) Integrating behavior and physiology into strategies for amphibian conservation. Front Ecol Evol 7:234

Webb JK, Letnic M, Jessop TS, Dempster T (2014) Behavioural flexibility allows an invasive vertebrate to survive in a semi-arid environment. Biol Lett 10:20131014

Wilson ADM, Krause J (2012a) Personality and metamorphosis: is behavioral variation consistent across ontogenetic niche shifts? Behav Ecol 23:1316-1323

Wilson ADM, Krause J (2012b) Metamorphosis and animal personality: a neglected opportunity. Trends Ecol Evol 27:529-531

Wilson MMG, Morley JE (2003) Impaired cognitive function and mental performance in mild dehydration. Eur J Clin Nutr 57:S24-S29

Publisher's note Springer Nature remains neutral with regard to jurisdictional claims in published maps and institutional affiliations.

\section{Affiliations}

\section{Carla B. Madelaire ${ }^{1,2}$ (D) Adriana M. G. Barsotti ${ }^{1,2}\left(\mathbb{D} \cdot\right.$ Carla Wagener $^{2}(\mathbb{D}) \cdot$ Yuri Y. Vieira Sugano $^{1}(\mathbb{D} \cdot$ James Baxter-Gilbert ${ }^{2}$ (D) $\cdot$ Fernando R. Gomes ${ }^{1}$ (D) $\cdot$ John $^{\text {Measey }}{ }^{2}$ (D)}

1 Instituto de Biociências, Departamento de Fisiologia, Universidade de São Paulo (USP), Rua do Matão, trav 14 n 321, Cidade Universitária, São Paulo, SP 05508-090, Brazil
2 Centre for Invasion Biology, Department of Botany and Zoology, Stellenbosch University, Stellenbosch, South Africa 